\title{
Survey of Plasmodium falciparum multidrug resistance-1 and chloroquine resistance transporter alleles in Haiti
}

Maha A ElBadry ${ }^{1}$, Alexandre Existe ${ }^{2}$, Yves S Victor $^{3}$, Gladys Memnon $^{4}$, Mark Fukuda ${ }^{5}$, John B Dame ${ }^{6}$, Charles A Yowell ${ }^{6}$ and Bernard A Okech ${ }^{1,7^{*}}$

\begin{abstract}
Background: In Haiti where chloroquine (CQ) is widely used for malaria treatment, reports of resistance are scarce. However, recent identification of CQ resistance genotypes in one site is suggestive of an emerging problem. Additional studies are needed to evaluate genetic mutations associated with CQ resistance, especially in the Plasmodium falciparum multi-drug resistance-1 gene (pfmdr1) while expanding the already available information on P. falciparum CQ transporter gene (pfcrt) in Haiti.

Methods: Blood samples were collected on Whatman filter cards (FTA) from eight clinics spread across Haiti. Following the confirmation of $P$. falciparum in the samples, PCR protocols were used to amplify regions of pfmdr1and pfcrt codons of interest, $(86,184,1034,1042$, and 1246) and (72-76), respectively. Sequencing and site-specific restriction enzyme digestions were used to analyse these DNA fragments for the presence of single nucleotide polymorphisms (SNPs) known to confer resistance to anti-malarial drugs.

Results: $P$. falciparum infection was confirmed in 160 samples by amplifying a segment of the $P$. falciparum 185 small subunit ribosomal RNA gene (pfssurrna). The sequence of pfmdr 1 in 54 of these samples was determined between codons 86,184 codons 1034, 1042 and 1246. No sequence differences from that of the NF54 clone 3D7 were found among the 54 samples except at codon 184, where a non-silent mutation was found in all samples predicted to alter the amino acid sequence replacing tyrosine with phenylalanine (Y184F). This altered sequence was also confirmed by restriction enzyme digestion. The sequence of pfmdr1 at codons 86, 184, 1034 and 1042 encoded the NFSN haplotype. The sequence of pfcrt codons $72-76$ from 79 samples was determined and found to encode CVMNK, consistent with a CQ sensitive genotype.
\end{abstract}

Conclusion: The presence of the $\mathrm{Y} 184 \mathrm{~F}$ mutation in $\mathrm{pfm} d r 1$ of $P$. falciparum parasites in Haiti may have implications for resistance to antimalarial drugs. The absence of mutation in pfcrt at codon 76 among 79 isolates tested suggests that sensitivity to CQ in Haiti remains common. Wide-spread screening of the pfmdr1 and pfcrt especially among patients experiencing treatment failure may be a useful tool in early detection of the emergence of antimalarial drug resistance in Haiti.

Keywords: Hispaniola, Chloroquine, Mefloquine, Anti-malarial drug resistance, Genotyping

\footnotetext{
*Correspondence: bokech@ufl.edu

'Department of Environmental and Global Health, University of Florida,

Gainesville, FL 32610, USA

${ }^{7}$ Emerging Pathogens Institute, University of Florida, Gainesville, FL 32610, USA

Full list of author information is available at the end of the article
} 


\section{Background}

An estimated 30,000 cases of malaria infections are reported annually in Haiti [1,2], where transmission is hypo-endemic with sporadic epidemics fueled by heavy rainfall. Malaria infections in Haiti are dominantly caused by Plasmodium falciparum [3,4]. Chloroquine (CQ) has been in use as an anti-malarial since the 1950s [5], and is currently used extensively in the treatment of malaria in Haiti [1]. Recently, a national malaria treatment policy revision added single dose primaquine to target gametocytes [1]. Despite long-term use, there are scarce reports of CQ-resistant P. falciparum malaria in Haiti [6-8]. However, the recent reports of CQ-resistant $P$. falciparum parasites harbouring known resistant alleles of pfcrt $[9,10]$ are alarming and could present serious challenges to clinical management of malaria in Haiti and diminish prospects for its elimination from Hispaniola (the Caribbean island where both Haiti and the Dominican Republic are located).

Research studies conducted more than three decades ago found only CQ sensitive P. falciparum strains [6,7], but very few follow-up studies have been conducted during the intervening years. In the recent past, a few studies identified the CQ-resistance-associated K76T mutation in the pfcrt at a very low prevalence in samples from the Artibonite valley, from Leogane, and from travellers returning from Haiti [8-10]. The potential role of resistant alleles of $p f m d r 1$ in CQ resistance in Haiti has yet to be investigated. In addition, there is a need to screen for the CQ resistance-associated pfcrt and $p f m d r 1$ alleles in other parts of Haiti.

Single nucleotide polymorphisms (SNPs) in the $p f m d r 1$ have been associated with resistance to CQ and other anti-malarial drugs including amodiaquine (AQ) and artemether-lumefantrine (AL). The P. falciparum glycoprotein homologue-1 found in the digestive vacuole of the malaria parasites is encoded by $p f m d r 1$ gene [11]. CQ diffuses to parasite food vacuole (FV) membrane neutrally where it protonates by acids present, which prevents free diffusion out the vacuole and results in accumulation of CQ in sensitive parasites. In CQ resistant parasites, changes in FV membrane proteins encoded by $p f c r t$ and $p f m d r 1$ genes are thought to play a role in reducing accumulation of drug inside the vacuole [11-14]. The role played by pfmdr1 mutations (N86Y, Y184F, S1034C and D1246Y) in mediating in vivo and in vitro CQ resistance has received a lot of research interest $[13,15-23]$. No previous reports have described alleles of $p f m d r 1$ that may be associated with anti-malarial drug resistance in Haiti. Therefore, this research study evaluated in Haiti the mutations in pfmdr1 that in other regions of the world are associated with resistance to CQ and expanded the surveillance locations in Haiti for CQ resistance mutations in $p f c r t$. This study complements the anti-malarial drug resistance surveillance efforts of the Haitian government.

\section{Methods}

\section{Study sites}

The sites where the samples originated are located in Port-au-Prince, Artibonite, North Cap Haitian, Leogane, Hinche and Jacmel (Figure 1). All sites are rural communities except the Port-au-Prince site, which is near the international airport. All locations suffer drastically from poor infrastructural facilities, which is common in Haiti. The average temperature in these sites ranges from $\left(22^{\circ} \mathrm{C}-35^{\circ} \mathrm{C}\right)$ all year round [24] which favors malaria vector breeding and consequently malaria transmission. Peak rainfall occurs between November and January [25], and the majority of malaria cases were sampled during this period.

\section{Sample collection}

Plasmodium falciparum malaria infected blood samples were collected by finger prick and preserved as dried blood spots (DBS) on FTA cards (Whatman GE Healthcare, MA, USA) between May 2010 and June 2012. Samples were obtained from patients attending study clinics, meeting the inclusion criteria (any patient above the age of two year old with malaria-like symptoms) who tested positive with rapid diagnostic test (CareStat ${ }^{\mathrm{Tm}}$ First Response Malaria Ag pLDH/HRP2 Combo card, Premier Medical Corporation, India) and microscopy for P. falciparum and agreed to sign a consent form. All patients received treatment according to the Haitian approved standard of care available at the clinics. The Haiti Ethical Review Board, University of Florida Institutional Review Board and the Office of Research Protections, US Army Medical Research and Material Command approved this study.

\section{DNA extraction}

Plasmodium falciparum DNA was extracted from the DBS with a methanol extraction wash protocol as previously described [26,27]. A single disc $3 \mathrm{~mm}$ in diameter was punched from the DBS and placed in a $0.2 \mathrm{ml}$ microcentrifuge tube. A volume of $100 \mu \mathrm{l}$ of absolute methanol was added and the tube incubated at room temperature for $15 \mathrm{~min}$. Methanol was then decanted and the $3 \mathrm{~mm}$ disc left to air dry for $30 \mathrm{~min}$. Sixty-five microlitres of sterile DNA-free grade water was then added to the dried disc, agitated slightly and then heated to $97^{\circ} \mathrm{C}$ for $30 \mathrm{~min}$. The tube was then centrifuged at low speed and the supernatant stored at $-20^{\circ} \mathrm{C}$ for use in the PCR amplification protocol.

\section{Detection of Plasmodium falciparum and amplification of pfmdr1 by PCR}

All samples were PCR tested to confirm the presence of $P$. falciparum by amplifying the small subunit ribosomal 


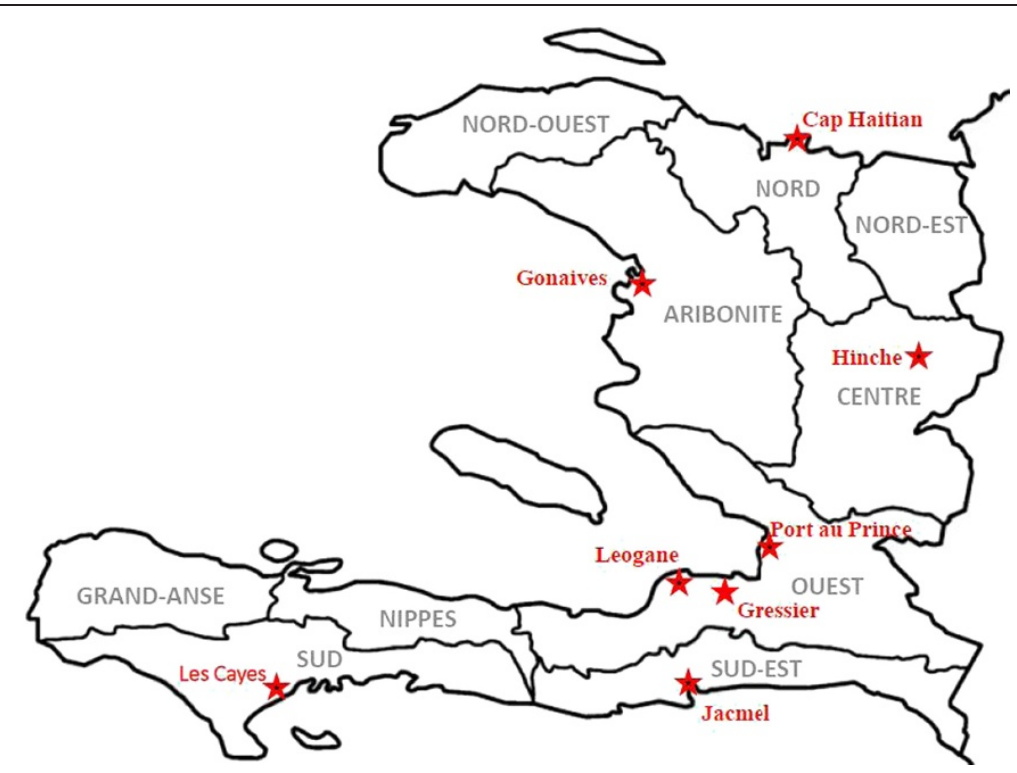

Figure 1 Map of Haiti showing sampling sites.

RNA (pfssurrna) gene [GenBank: KC906718.1] of $P$. falciparum with a one-step PCR as previously described [10]. Confirmed P. falciparum positive samples were subsequently used for amplification of segments of $p f m d r 1$ encoding five codons of interest; 86, 184, 1034, 1042 and 1246 using a nested PCR protocol as previously described [28]. All primer sequences used to amplify segments of pfmdr1 are listed in Table 1. All PCR reactions included the following reagents: $1 \mathrm{x}$ Taq PCR Master Mix, $0.2 \mathrm{mM}$ dNTPs, $0.75 \mathrm{mM} \mathrm{MgCl}_{2}$, and $0.2 \mu \mathrm{M}$ of each primer. The temperature protocol used for each reaction were as follows: one cycle at $94^{\circ} \mathrm{C}$ for 2 minutes, an amplification for 35 cycles $\left(94^{\circ} \mathrm{C}\right.$ for $30 \mathrm{sec}, 45^{\circ} \mathrm{C}$ for $1 \mathrm{~min}$, and $72^{\circ} \mathrm{C}$ for $1 \mathrm{~min}$ ) and a final extension at $72^{\circ} \mathrm{C}$ for $5 \mathrm{~min}$. Two microlitres of the product of the initial PCR was used as a template for the nested second PCR reaction in all regions. The products of the nested PCR were electrophoresed in
$2 \%$ agarose gels, stained with ethidium bromide $(\mathrm{EtBr})$ and visualized with a BioRad Transluminator (Universal Hood II). Amplification products were used in restriction digest analysis and sequenced as described below.

\section{Restriction enzyme digestion for pfmdr1 mutations}

The pfmdr1 amplification products were subjected to restriction enzyme digestion. The restriction enzymes used included Apo I/Afl III, Dra I, Dde I, AseI and EcoRV for analysis of sequences at codons 86, 184, 1034, 1042 and 1246, respectively. All enzymes were purchased from New England Biolabs (Ipswich, MA, USA). Technique was performed as previously described [28,29]. Digestion was carried out according to manufacturer instructions. The product of digestion was resolved on a $2.5 \%$ agarose gel and visualized with BioRad Transilluminator (Universal Hood II).

Table 1 The PCR amplification primers list for pfmr1 and pfort used in the study

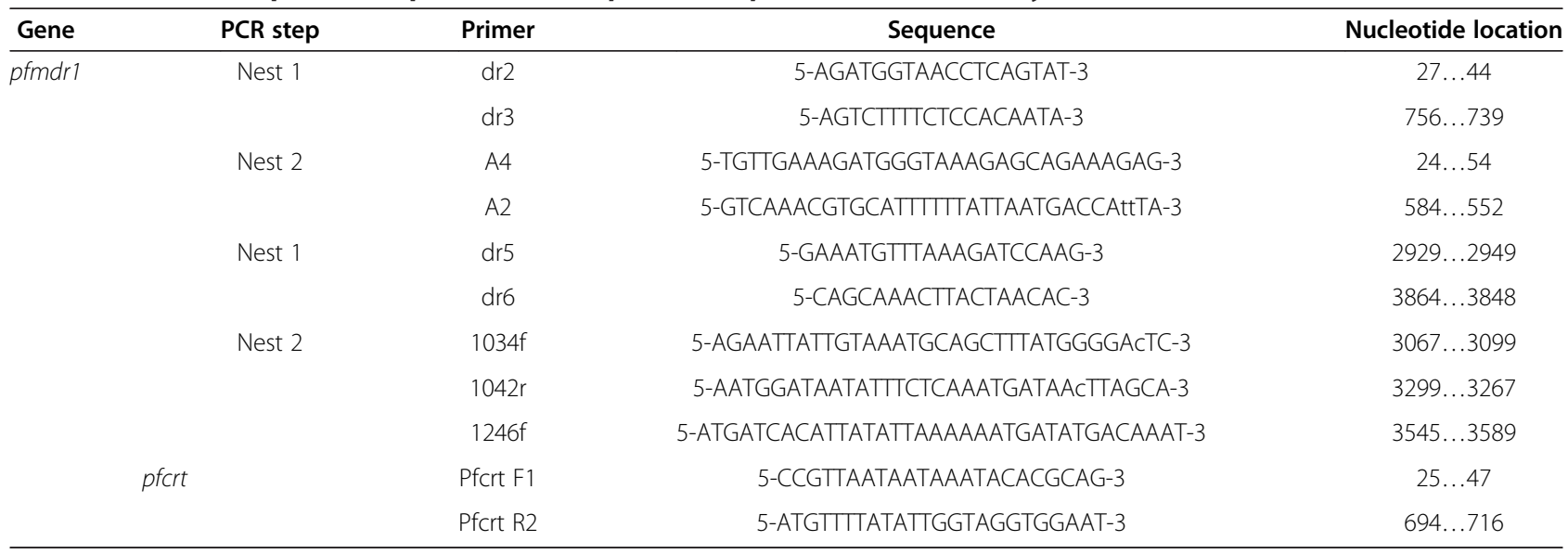




\section{Amplification of pfcrt}

Samples positive for pfssurrna were used to amplify codons 72-76 of pfcrt gene as previously described [10,30]. A one-step PCR was carried out using Phusion flash high fidelity master mix from (New England Biolabs, Ipswich, MA,USA) with a $25 \mu$ l final volume of PCR reaction composed of $1 \mathrm{x}$ PCR Master Mix containing $0.2 \mathrm{mM}$ dNTPs, $0.5 \mu \mathrm{M}$ each primer, $2.5 \mathrm{mM} \mathrm{MgCl} 2$, and $1 \mu \mathrm{l}$ of DNA extract. The cycling temperature protocol used was: two cycles at $95^{\circ} \mathrm{C}$ for $5 \mathrm{~min}$, amplification for 40 cycles $\left(94^{\circ} \mathrm{C}\right.$ for $30 \mathrm{sec}, 60^{\circ} \mathrm{C}$ for $30 \mathrm{sec}$, and $72^{\circ} \mathrm{C}$ for $30 \mathrm{sec}$ ) and a final extension at $72^{\circ} \mathrm{C}$ for $10 \mathrm{~min}$. Products of amplification were then electrophoresed on $2 \%$ agarose gel, stained with $\mathrm{EtBr}$ and visualized with BioRad Transilluminator (Universal Hood II).

\section{Sequencing and alignment}

Amplified segments of $p f m d r 1$ and $p f c r t$ were sequenced by the Sanger chain-termination method to determine polymorphic sites associated with CQ or other antimalarial resistance. Sequencing was done on a Biosystem 3730 Genetic Analyzer at the University of Florida's Interdisciplinary Center for Biotechnology Research DNA Sequencing Core Laboratory. All sequences results were aligned to P. falciparum 3D7 pfmdrland pfcrt sequences. [GenBank: NC_004326.1 and NC_004328.2] respectively.

\section{Results}

A total of 375 microscopy-confirmed positive samples for $P$. falciparum were collected for analysis by PCR. A segment of the pfssurrna gene was successfully amplified from 160 of these samples. One or more segments of interest from the $p f m d r 1$ gene were successfully amplified for sequence analysis from 54 samples. No mutations were detected in codons 86, 1034, 1042 and 1246 among the samples in which codons were successfully amplified. However, mutations were found at codon $184(\mathrm{Y} \rightarrow \mathrm{F})$ in all the samples in which the codon successfully amplified which was further confirmed by restriction enzyme digestion. The number of samples that successfully amplified for each codon per site is shown in Table 2 . Thirty-eight samples that amplified at codons 86, 184, 1034 and 1042 were all NFSN haplotype. In the analysis of $p f c r t$, the polymorphic region associated with CQ resistance alleles, encompassing codons 72-76, was successfully amplified from 79 samples. No mutations were detected with all samples expressing the wild type sequence CVMNK. The intersection of samples from which both alleles-pfcrt and pfmdr1-successfully amplified were 50 .

\section{Discussion}

Although this study was limited by small sample size, it provides preliminary information about the pfmdr1 alleles in Haiti and adds additional data on $p f c r t$ alleles in parasites from both previously sampled regions of Haiti and from regions not previously sampled. This study is the first to examine in Haiti the pfmdr1 genetic mutations linked to anti-malarial drug resistance in other regions of the world. This study found neither the K76T mutation in pfcrt nor the N86Y, S1034C, N1042D or D1246Y mutations in $p f m d r 1$, that have been reported to confer resistance to CQ [22,23,31-33]. The absence of mutations at codons 1034 and 1042 in pfmdrl suggests that the $P$. falciparum parasites analysed in this study likely remain sensitive to mefloquine [34] and AL [35]. Interestingly, all the samples tested had a Y $->$ F mutation in codon 184 in $p f m d r 1$. The widespread occurrence of this single mutation in $p f m d r 1$ is not unique in the literature [36,37]. Previous studies of clinical isolates of $P$. falciparum in Cambodia reported a similar widespread occurrence of single point mutations, and the mutation resulting in the Y184F mutation was predominant over other pfmdr1 mutations [38].

Although the Y184F mutation in pfmdr1 has been associated mainly with low level resistance to AL [39], there is no consensus in the literature for its role in CQ resistance $[28,34,40]$. In a previous study [15], the Y184F polymorphism was shown to play a role in CQ resistance in close association with the K76T mutation in pfcrt. The Y184F mutation is thought to alter the

Table 2 Presents summary of PCR amplification results and geographic distribution of samples collected in the study, number of samples amplified for different genes pfssurrna, pfcrt, and differential data on no. of samples amplified for different codons of pfmdr1

\begin{tabular}{|c|c|c|c|c|c|c|c|}
\hline Site & $\begin{array}{l}\text { No. of samples positive } \\
\text { for microscopy }\end{array}$ & $\begin{array}{l}\text { Positive for } \\
\text { pfssurrna }\end{array}$ & $\begin{array}{l}\text { Positive } \\
\text { for } p f c r t\end{array}$ & Codon $86-184$ & Codon 1034-1042 & Codon 1246 & $\begin{array}{l}\text { No. of samples amplified } \\
\text { for codons } 86-1042\end{array}$ \\
\hline Port-au-Prince & 251 & 70 & 39 & 29 & 27 & 8 & 23 \\
\hline Leogane & 40 & 39 & 17 & 8 & 11 & 1 & 4 \\
\hline Cap Haitian & 10 & 2 & 3 & 0 & 1 & 0 & 0 \\
\hline L'Cay Jacmel & 17 & 16 & 15 & 13 & 9 & 0 & 8 \\
\hline Artibonite & 50 & 26 & 3 & 2 & 2 & 0 & 1 \\
\hline Nippes & 7 & 7 & 2 & 2 & 3 & 0 & 2 \\
\hline Total & 375 & 160 & 79 & 54 & 53 & 9 & 38 \\
\hline
\end{tabular}


kinetics of anti-malarial drug transport [32,41], and thus efficacy. The absence of the K76T mutations in the study sample indicates that the Y184F mutation in pfmdr1 is rarely found in Haiti in combination with K76T in pfcrt. Although this $p f m d r 1$ allele may not alone increase CQ resistance, it's high prevalence could have an impact if the frequency of the pfcrt $\mathrm{K} 76 \mathrm{~T}$ allele were to increase in Haiti [8]. Other studies have shown a modification of resistance to AL in P. falciparum with the Y184F mutation under a N86Y and D1246Y background [36]. The absence of N86Y, S1034C, N1042D or D1246Y in pfmdr1 alleles in this study sustains CQ or AL sensitivity in Haiti. Therefore, the findings would seem to indicate that the presence of the Y184F mutation alone would not contribute greatly to anti-malarial resistance in Haiti in the absence of wide spread K76T mutations in pfcrt or additional mutations in pfmdr1. Routine molecular surveillance of the anti-malarial drug resistance genes in Haiti combined with in vitro drug sensitivity studies are needed to ascertain the sensitivity of Haitian P. falciparum strains to the major anti-malarial medications in use in Haiti and other parts of world.

The recent reports of CQ resistance genotypes in Haiti are alarming for public health officials in Haiti and concerted efforts are needed to monitor the anti-malaria drug resistance genotypes in Haiti. The results of this study have provided background data on $p f m d r 1$, which may be referenced in discussions of future $P$. falciparum anti-malarial resistance patterns in Haiti. This study also provides additional data on the prevalence of the $p f c r t$ K76T allele in Haiti, but additional studies are needed to increase the sample size and provide an accurate estimate for K76T allele prevalence and distribution. Nonetheless, the findings in this study have increased the knowledge of two important anti-malaria drug resistance markers in Haiti, where widespread drug resistance has not yet been observed.

\section{Study limitations}

The small sample size is indeed the largest limitation of this study, however due to the difficulty of the study initiation; proper sample storage for the FTA cards was lacking which affected the quality of DNA. The study lack adequate sample distribution, were some sites failed to enroll sufficient number of patients, this can be attributed to change in site administration which affected the study enrollment.

\section{Competing interests}

The authors declare they have no competing interest.

\section{Authors' contributions}

MAE generated the molecular data and interpretation, contributed to writing of the manuscript. AE organized sample collection in Haiti. YV organized sample collection at Blanchard clinic. GM organized sample collection in Hospital Saint Croix. MF reviewed data and writing of manuscript. JD participated in writing manuscript. CY worked on genotyping of samples. BO designed the study, drafted manuscript, coordinated the sample collection, and data analysis. All authors read and approved the final manuscript.

\section{Acknowledgements}

The authors thank the Haiti Ministry of Sanitation and Public Practice (MSPP), Christianville Foundation Haiti, Family Health Ministries, Haiti, Hospital Sainte Croix and Blanchard Clinic in Haiti for their support in the execution of this work. The work in this paper was supported by a grant from the Department of Defense (DoD) Global Emerging Infections Surveillance \& Response System (GEIS) Grant \# P0103_13__UN awarded to BAO.

\section{Author details}

${ }^{1}$ Department of Environmental and Global Health, University of Florida, Gainesville, FL 32610, USA. ${ }^{2}$ National Public Health Laboratory, Ministry of Public Health and Population, Port au Prince, Haiti. ${ }^{3}$ Blanchard Clinic, Family Health Ministries Haiti, Terre Noire, Port au Prince, Haiti. ${ }^{4}$ Hospital Saint Croix, Leogane, Haiti. ${ }^{5}$ Armed Forces Health Sciences Surveillance Center, Silver Spring, MD, USA. ${ }^{6}$ Department of Infectious Diseases and Pathology, University of Florida Gainesville, Gainesville, FL 32610, USA. ${ }^{7}$ Emerging Pathogens Institute, University of Florida, Gainesville, FL 32610, USA.

Received: 17 August 2013 Accepted: 25 October 2013

Published: 19 November 2013

\section{References}

1. WHO: World Malaria Report 2012. Geneva: World Health Organization; 2012.

2. Roberts L: Elimination meets reality in Hispaniola. Science 2010, 328:850-851.

3. Eisele TP, Keating J, Bennett A, Londono B, Johnson D, Lafontant C, Krogstad DJ: Prevalence of Plasmodium falciparum infection in rainy season, Artibonite Valley, Haiti, 2006. Emerg Infect Dis 2007, 13:1494-1496.

4. Raccurt C: Malaria in Haiti today](in French). Sante 2004, 14:201-2014.

5. Mason J: Development of the Haiti malaria eradication programme. World Health Organization technical document. WHO/Mal; 1968:68.665.

6. Duverseau YT, Magloire R, Zevallos-Ipenza A, Rogers HM, Nguyen-Dinh P: Monitoring of chloroquine sensitivity of Plasmodium falciparum in Haiti, 1981-1983. Am J Trop Med Hyg 1986, 35:459-464.

7. Magloire R, Nguyen-Dinh P: Chloroquine susceptibility of Plasmodium falciparum in Haiti. Bull World Health Organ 1983, 61:1017-1020.

8. Neuberger A, Zhong K, Kain KC, Schwartz E: Lack of evidence for chloroquine-resistant Plasmodium falciparum malaria, Leogane, Haiti. Emerg Infect Dis 2012, 18:1487-1489.

9. Gharbi M, Pillai DR, Lau R, Hubert V, Khairnar K, Existe A, Kendjo E, Dahlström S, Guérin PJ, Le Bras J, French National Reference Center for Imported Malaria Study: Chloroquine-resistant malaria in travelers returning from Haiti after 2010 earthquake. Emerg Infect Dis 2012, 18:1346-1349.

10. Londono BL, Eisele TP, Keating J, Bennett A, Chattopadhyay C, Heyliger G, Mack B, Rawson I, Vely JF, Désinor O, Krogstad DJ: Chloroquine-resistant haplotype Plasmodium falciparum parasites, Haiti. Emerg Infect Dis 2009, 15:735-740.

11. Cowman AF, Karcz S, Galatis D, Culvenor JG: A P-glycoprotein homologue of Plasmodium falciparum is localized on the digestive vacuole. J Cell Biol 1991, 113:1033-1042.

12. Reed MB, Saliba KJ, Caruana SR, Kirk K, Cowman AF: Pgh1 modulates sensitivity and resistance to multiple anti-malarials in Plasmodium falciparum. Nature 2000, 403:906-909.

13. Rohrbach P, Sanchez CP, Hayton K, Friedrich O, Patel J, Sidhu AB, Ferdig MT, Fidock DA, Lanzer M: Genetic linkage of pfmdr1 with food vacuolar solute import in Plasmodium falciparum. EMBO J 2006, 25:3000-3011.

14. Ehlgen F, Pham JS, de Koning-Ward T, Cowman AF, Ralph SA: Investigation of the Plasmodium falciparum food vacuole through inducible expression of the chloroquine resistance transporter (PfCRT). PLoS One 2012, 7:e38781.

15. Foote SJ, Kyle DE, Martin RK, Oduola AM, Forsyth K, Kemp DJ, Cowman AF: Several alleles of the multidrug-resistance gene are closely linked to chloroquine resistance in Plasmodium falciparum. Nature 1990, 345:255-258.

16. Basco LK, Le Bras J, Rhoades Z, Wilson CM: Analysis of pfmdr1 and drug susceptibility in fresh isolates of Plasmodium falciparum from subsaharan Africa. Mol Biochem Parasitol 1995, 74:157-66.

17. Adagu IS, Dias F, Pinheiro L, Rombo L, do Rosario V, Warhurst DC: Guinea Bissau: association of chloroquine resistance of Plasmodium falciparum 
with the Tyr86 allele of the multiple drug-resistance gene Pfmdr1. Trans R Soc Trop Med Hyg 1996, 90:90-91.

18. von Seidlein L, Duraisingh MT, Drakeley CJ, Bailey R, Greenwood BM, Pinder M: Polymorphism of the Pfmdr1 gene and chloroquine resistance in Plasmodium falciparum in The Gambia. Trans R Soc Trop Med Hyg 1997, 91:450-453.

19. Duraisingh MT, Drakeley CJ, Muller O, Bailey R, Snounou G, Targett GA, Greenwood BM, Warhurst DC: Evidence for selection for the tyrosine-86 allele of the pfmdr 1 gene of Plasmodium falciparum by chloroquine and amodiaquine. Parasitology 1997, 114:205-211.

20. Bhattacharya PR, Biswas S, Kabilan L: Alleles of the Plasmodium falciparum Pfmdr1 gene appear not to be associated with chloroquine resistance in India. Trans R Soc Trop Med Hyg 1997, 91:454-455.

21. Andriantsoanirina V, Ratsimbasoa A, Bouchier C, Jahevitra M, Rabearimanana S, Radrianjafy R, Andrianaranjaka V, Randriantsoa T, Rason MA, Tichit M, Rabarijaona LP, Mercereau-Puijalon O, Durand R, Ménard D: Plasmodium falciparum drug resistance in Madagascar: facing the spread of unusual pfdhfr and pfmdr-1 haplotypes and the decrease of dihydroartemisinin susceptibility. Antimicrob Agents Chemother 2009, 53:4588-4597.

22. Duraisingh MT, Cowman AF: Contribution of the pfmdr1 gene to anti-malarial drug-resistance. Acta Trop 2005, 94:181-190.

23. Khalil IF, Alifrangis M, Tarimo DS, Staalsø T, Satti GM, Theander TG, Rønn AM, Bygbjerg IC: The roles of the pfcrt $76 \mathrm{~T}$ and pfmdr1 $86 \mathrm{Y}$ mutations, immunity and the initial level of parasitaemia, in predicting the outcome of chloroquine treatment in two areas with different transmission intensities. Ann Trop Med Parasitol 2005, 99:441-448.

24. Climate \& Temperature. ; 2012. Available from: http://www.haiti.climatemps.com/

25. Karabanow A: Malaria in Haiti. 2012. Haiti: Port Au Prince: Crudem Hopital Sacre Coeur; 2012.

26. Bereczky S, Mårtensson A, Gil JP, Färnert A: Rapid DNA extraction from archive blood spots on filter paper for genotyping of Plasmodium falciparum. Am J Trop Med Hyg 2005, 72:249-251.

27. Carter TE, Warner M, Mulligan CJ, Existe A, Victor YS, Memnon G, Boncy J, Oscar R, Fukuda MM, Okech BA: Evaluation of dihydrofolate reductase and dihydropteroate synthetase genotypes that confer resistance to sulphadoxine-pyrimethamine in Plasmodium falciparum in Haiti. Malar $\rfloor$ 2012, 11:275.

28. Huaman MC, Roncal N, Nakazawa S, Long TT, Gerena L, Garcia C, Solari L, Magill AJ, Kanbara H: Polymorphism of the Plasmodium falciparum multidrug resistance and chloroquine resistance transporter genes and in vitro susceptibility to aminoquinolines in isolates from the Peruvian Amazon. Am J Trop Med Hyg 2004, 70:461-466.

29. Duraisingh MT, Jones P, Sambou I, von Seidlein L, Pinder M, Warhurst DC: The tyrosine- 86 allele of the pfmdr1 gene of Plasmodium falciparum is associated with increased sensitivity to the anti-malarials mefloquine and artemisinin. Mol Biochem Parasitol 2000, 108:13-23.

30. Takahashi N, Tanabe K, Tsukahara T, Dzodzomenyo M, Dysoley L, Khamlome B, Sattabongkot J, Nakamura M, Sakurai M, Kobayashi J, Kaneko A, Endo H, Hombhanje F, Tsuboi T, Mita T: Large-scale survey for novel genotypes of Plasmodium falciparum chloroquine-resistance gene pfcrt. Malar J 2012, 11:92.

31. Andriantsoanirina V, Ratsimbasoa A, Bouchier C, Tichit M, Jahevitra M, Rabearimanana S, Raherinjafy R, Mercereau-Puijalon O, Durand R, Ménard D: Chloroquine clinical failures in $\mathrm{P}$. falciparum malaria are associated with mutant Pfmdr-1, Not Pfcrt in Madagascar. PLoS One 2010, 5:e13281.

32. Sanchez $C P$, Rotmann $A$, Stein WD, Lanzer M: Polymorphisms within PfMDR1 alter the substrate specificity for anti-malarial drugs in Plasmodium falciparum. Mol Microbiol 2008, 70:786-798.

33. Sidhu AB, Verdier-Pinard D, Fidock DA: Chloroquine resistance in Plasmodium falciparum malaria parasites conferred by pfcrt mutations. Science 2002, 298:210-213.

34. Sidhu AB, Valderramos SG, Fidock DA: pfmdr1 mutations contribute to quinine resistance and enhance mefloquine and artemisinin sensitivity in Plasmodium falciparum. Mol Microbiol 2005, 57:913-926.

35. Sá JM, Twu O, Hayton K, Reyes S, Fay MP, Ringwald P, Wellems TE: Geographic patterns of Plasmodium falciparum drug resistance distinguished by differential responses to amodiaquine and chloroquine. Proc Natl Acad Sci U S A 2009, 106:8883-8889.

36. Nkhoma S, Nair S, Mukaka M, Molyneux ME, Ward SA, Anderson TJ: Parasites bearing a single copy of the multi-drug resistance gene (pfmdr-1) with wild-type SNPs predominate amongst Plasmodium falciparum isolates from Malawi. Acta Trop 2009, 111:78-81.
37. Thomsen TT, Ishengoma DS, Mmbando BP, Lusingu JP, Vestergaard LS, Theander TG, Lemnge MM, Bygbjerg IC, Alifrangis M: Prevalence of single nucleotide polymorphisms in the Plasmodium falciparum multidrug resistance gene (Pfmdr-1) in Korogwe District in Tanzania before and after introduction of artemisinin-based combination therapy. Am J Trop Med Hyg 2011, 85:979-983.

38. Khim N, Bouchier C, Ekala MT, Incardona S, Lim P, Legrand E, Jambou R, Doung S, Puijalon OM, Fandeur T: Countrywide survey shows very high prevalence of Plasmodium falciparum multilocus resistance genotypes in Cambodia. Antimicrob Agents Chemother 2005, 49:3147-3152.

39. Chavchich M, Gerena L, Peters J, Chen N, Cheng Q, Kyle DE: Role of pfmdr1 amplification and expression in induction of resistance to artemisinin derivatives in Plasmodium falciparum. Antimicrob Agents Chemother 2010, 54:2455-2464

40. Cox-Singh J, Singh B, Alias A, Abdullah MS: Assessment of the association between three pfmdr1 point mutations and chloroquine resistance in vitro of Malaysian Plasmodium falciparum isolates. Trans $R$ Soc Trop Med Hyg 1995, 89:436-437.

41. Hayward R, Saliba KJ, Kirk K: Mutations in pfmdr1 modulate the sensitivity of Plasmodium falciparum to the intrinsic antiplasmodial activity of verapamil. Antimicrob Agents Chemother 2005, 49:840-842.

\section{doi:10.1186/1475-2875-12-426}

Cite this article as: ElBadry et al.: Survey of Plasmodium falciparum multidrug resistance- 1 and chloroquine resistance transporter alleles in Haiti. Malaria Journal 2013 12:426.

\section{Submit your next manuscript to BioMed Central and take full advantage of:}

- Convenient online submission

- Thorough peer review

- No space constraints or color figure charges

- Immediate publication on acceptance

- Inclusion in PubMed, CAS, Scopus and Google Scholar

- Research which is freely available for redistribution

Submit your manuscript at www.biomedcentral.com/submit
C Biomed Central 